\title{
The prevalence of sexual dysfunctions in infertile women
}

Naeimeh Tayebi, M.D.*

Seyed Mojtaba Yassini Ardakani, M.D. ${ }^{\dagger}$

Research and Clinical Center for Infertility, Shahid Sadoughi University of Medical Science, Yazd, Iran.

\begin{abstract}
Objective: Sexuality is an important and integral part of every woman's life. The aim of this study was to assess the degree of sexual dysfunction among infertile women and its correlation with age, duration of marriage and etiology of infertility in women.

Materials and Methods: 300 infertile women who were referred to IVF center for management of their infertility problem involved in this study after informed consent. They were asked to fill a questionnaire that contained three parts of demographic, infertility and sexual function items. Distribution of sexual dysfunction and its relationship to infertility and marriage duration were analyzed through SPSS software.

Results: The most common sexual dysfunction was orgasm disorder (83.76\%) and the rate of sexual desire disorder, dyspareunia and vaginismus were $80.7 \%, 67.7 \%$ and $76.7 \%$ respectively. More than 50\% of cases mentioned decreased frequency of coitus after diagnosis of infertility. Vaginismus and dyspareunia were more common in 2024 years age group.

Conclusion: According to the high rate of sexual dysfunction in this study and almost the same rate in other studies, gynecologists should pay more attention to this important issue and encourage the patients to have an evaluation by a psychiatrist or psychologist
\end{abstract}

Keywords: Sexual dysfunction, infertility.

The sexual response cycle in women is mediated by the complex interplay of psychological, environmental, and physiologic (hormonal, vascular, muscular, and neurological) factors. The initial phase of the sexual response cycle is interest and desire, followed by the four successive phases originally described by Masters and Johnson: arousal, plateau, orgasm, and resolution (1).

Types of sexual disorders that are more common in women include: a) sexual desire disorders b) sexual arousal disorders c) orgasmic

\footnotetext{
*Medical Doctor, Research and Clinical Center for Infertility, Shahid Sadoughi University. Yazd, Iran

${ }^{\dagger}$ Assistant Professor of psychiatry, Research and Clinical Center for Infertility, Shahid Sadoughi University of Medical Science, Yazd, Iran.

Correspondence: Naeimeh Tayebi, Email: ntayebi@yahoo.com
}

disorders d) sexual pain disorders (vaginismus, dyspareunia) (2, 3).

There is a complex association between sexual behavior and infertility. Sexual dysfunction can cause a delay in conception, but can also be the result of not conceiving. The greatest chance of conception is achieved through sexual intercourse on multiple occasions during the fertile period (4).

Infertility may be the result of sexual problems. Therefore, infertility examination should include an evaluation of couple's sexual behavior $(5,6)$.

In many cases, all infertility treatments have to be stopped and psychological aid has to be offered for sexual dysfunction (7).

Infertile women are likely to suffer from numerous psychosexual problems. Elstein has described the infertile couples as potentially having abnormalities of sexual function. Such abnormalities 
Table1. The prevalence of sexual problems in infertile women.

\begin{tabular}{lcc}
\hline & $\mathrm{N}$ & $\%$ \\
& 300 & \\
\hline Libido & 242 & 80.7 \\
No & 58 & 19.3 \\
Yes & & \\
No & 251 & 83.7 \\
Yes & 49 & 16.3 \\
Sexual arousal & & \\
No & 75 & 25 \\
Yes & 225 & 75 \\
Vaginismus & & \\
No & 70 & 23.3 \\
Yes & 230 & 76.7 \\
Dyspareunia & & \\
No & 97 & 32.3 \\
Yes & 203 & 67.7 \\
\hline
\end{tabular}

may have a cause and effect relationship with infertility, or they may be incidental to infertility, or they may be presented in the disguise of infertility (8).

Some studies on sexual problems of infertile couples are available in the literature $(9,10,11)$.

The objective of this study was to assess the degree of sexual dysfunction among infertile women and its correlation with age, duration of marriage and etiology of infertility in women.

\section{MATERIALS AND METHODS}

Female partners of 300 consecutive infertile couples were attended in this study from January to October 2006. Permission to perform this study was obtained from the ethics board of the committee of Yazd Research and Clinical Center for Infertility. The subjects volunteered as participants after the purpose of this study and the degree of the participation was explained to them, and then consents were signed.

All of the educated women filled the questionnaires by themselves and the rest of them (illiterate women) were interviewed by the first author personally. The questions of the questionnaire were grouped as follows:
1. Infertility status such as duration of marriage and infertility, type of infertility and personal data such as the age of the couple.

2. Sexual history such as frequency of intercourse, problems of desire, arousal and orgasm phases.

3. Past history such as referring to the psychiatrist previously.

Finally, the data were analyzed statistically with the aid of SPSS and chi-square test. The differences were considered to be statistically significant if $\mathrm{P}$-value was $<0.05$.

\section{RESULTS}

All women welcomed this detailed questioning about sexual problems and co-operated well.

The mean age of women and men were $27.93 \pm 4.8$ and $33.48 \pm 5.6$ years respectively. The duration of marriage and infertility were $7.56 \pm 4.3$ and $5.42 \pm 3.2$ years respectively. The type of infertility was $81 \%$ primary and $19 \%$ secondary. The etiology of infertility was $40 \%$ male factor, $44.3 \%$ female factor, $7.7 \%$ unknown and $8 \%$ mixed factors.

The prevalence of the sexual problems has been shown in Table 1 .

$58.3 \%$ of women and men mentioned a reduction in sexual desire after infertility diagnosis while $10.3 \%$ of women and $18.7 \%$ of men had an increase in sexual desire after infertility diagnosis.

In this study, the mode of intercourse frequency per week was 2 times. The intercourse frequency had reduced in $54 \%$ of women and had increased in 5.3\% after infertility diagnosis.

There was a significant difference between libido, achieving orgasm, dyspareunia and vaginismus with the age of women. (Table2).

In addition, Table 3 showed that the prevalence of vaginismus and dyspareunia has reduced with increasing duration of marriage.

There was no significant difference between sexual problems and etiology of infertility (Pvalue $=0.2$ ) $85 \%$ of women hadn't referred to the psychiatrist because of sexual problems in this research. 
Table 2. The association between sexual problems and the age of infertile women.

\begin{tabular}{lcccc}
\hline & $20-24$ year & $25-29$ year & $>30$ year & P-value \\
\hline $\begin{array}{l}\text { Total of patients } \\
\text { Libido }\end{array}$ & 75 & 127 & 98 & 0.009 \\
No & $60(80 \%)$ & $104(81.9 \%)$ & $78(79.6 \%)$ & \\
Yes & $15(20 \%)$ & $23(18.1 \%)$ & $20(20.4 \%)$ & 0.049 \\
Achieving orgasm & $59(78.7 \%)$ & $103(81.1 \%)$ & $89(90.8 \%)$ & 0.014 \\
No & $16(21.3 \%)$ & $24(18.9 \%)$ & $9(9.2 \%)$ & \\
Yes & $14(18.7 \%)$ & $46(36.2 \%)$ & $37(37.8 \%)$ & 0.028 \\
Dyspareunia & $61(81.3 \%)$ & $81(63.8 \%)$ & $61(62.6 \%)$ & \\
No & & & \\
Yes & $57(76 \%)$ & $29(22.8 \%)$ & $23(23.5 \%)$ & \\
Vaginismus & $18(24 \%)$ & $98(77.2)$ & $75(76.5 \%)$ & \\
No & & & \\
Yes & &
\end{tabular}

\section{DISCUSSION}

Infertility may interact with a woman's sexual expression by causing or exacerbating sexual problems as a consequence of the diagnosis, investigation and treatment of infertility. Conversely, sexual problems may contribute in infertility. However, it is important to bear in mind that a sexual problem is a disorder only if the women perceives it to be so, with impaired sexual desire as the most common presentation (12).

In our study, the most common sexual problems in infertile females were anorgasmia (83.7\%) and decreased libido (80.7\%) while Jindal et al (1996) with evaluation of 200 Indian infertile women showed that decreased frequency of intercourse and anorgasmia were the most common problems identified (13).

Table 3. The association between vaginismus and dyspareunia with duration of marriage.

\begin{tabular}{lrcc}
\hline & $<$ yyear & $>8$ year & P-value \\
\hline Dyspareunia & & & 0.02 \\
No & $42(26.9 \%)$ & $55(38.2 \%)$ & \\
Yes & $114(73.1 \%)$ & $89(61.8 \%)$ & \\
Vaginismus & & & 0.04 \\
No & $36(23.1 \%)$ & $110(76.4 \%)$ & \\
Yes & $120(76.9 \%)$ & $34(23.6 \%)$ & \\
\hline
\end{tabular}

The prevalence of difficulty with sexual arousal, dyspareunia were $25 \%$ and $67.7 \%$ respectively while Audu's study (2002) on 97 Nigerian infertile women showed that the prevalence of difficulty with sexual arousal and dyspareunia was $20.6 \%$ and $57.7 \%$ respectively (14).

Jain and associates (2000) have indicated that sexual problems in infertile women consisting of dyspareunia, decreased libido, and orgasmic failure were the most common problems in their study (15).

In our previous study on fertile women, $30 \%$ of patients didn't have sexual desire. 26.1\% weren't able to achieve orgasm and $17.1 \%$ had problem with sexual arousal. Also, $47.1 \%$ and $23.5 \%$ had dyspareunia and vaginismus respectively (16).In recent study, the prevalence of all sexual problems has increased in infertile women with comparison to fertile women.

Ponholzer et al (2005) showed that the prevalence of pain disorders were more frequent in women aged 20-39 years. Also, in their study, the prevalence of female sexual dysfunction increased with increasing age of women (17). In our study, the prevalence of pain disorders such as vaginismus and dyspareunia were more in women aged 20-24 years than the other groups.

Ramazanzadeh et al (2006) concluded that sexual desire and frequency of coitus has reduced in 200 male partners of infertile couples after infertility diagnosis (18) while our results indicated 
that sexual desire and frequency of coitus in infertile women has reduced significantly after infertility diagnosis.

In this study, only $15 \%$ of patients had been referred to the psychiatrist because of sexual problems. Despite the importance of these issues to their health care, many women find it difficult to talk to the physicians about sexual concerns, and many physicians are uncomfortable discussing sexual issues with their patients (19).

\section{ACKNOWLEDGMENT}

The authors express their thanks to Fatemeh Mosavi for her cooperation.

\section{REFERENCES}

1. Masters WH, Johnson VE. Human sexual response. Boston: Little, Brown, 1996.

2. American Psychiatric Association. Diagnostic And statistical manual of mental disorders, (4th Ed). Washington, DC: American Psychiatric Association,1994.

3. Basson R, Berman J, Burnett A, Derogatis L, Ferguson D, Fourcroy J, et al. Report on thé international consensus development conference on female sexual dysfunction: définition and classification. J Urol 2000; 163:688-893.

4. Gianotten WL, Te Velde ER. The influence of sexual function on the chance of pregnancy. Ned Tijdschr Geneeskd.2005, 28; 149:1207-10.

5. Berger DM. The role of the psychiatrist in a reproductive biology clinic. Fertil Steril 1977;28:141.
6. Palti Z. Psychogenic male infertility. Psychosom Med 1969; 31:326.

7. $\quad$ Sigg C. Sexuality and sterility. Ther Umsch. 1994;51:115-9.

8. Elstein M. Effect of sterility on psychosexual function. J Br Med.1975, 3:296.

9. McGrade JJ, Tolas A. The reaction to infertility and the infertility investigator: A comparison of the response of men and women. Infertility 1981;23: 4-7

10. Keye WR Jr. Psychosexual responses to infertility. Clin Obstet Gynecol.1984:27:760.

11. Ellsworth LR, Shain RN. Psychosocial and psychophysiology aspects of reproduction-the need for improved study design. Fertil Steril. 1985; 44:449.

12. Reader F. Disorders of female sexuality. In: progress in obstetrics and gynaecology, vol9, edited by Studd J, 1991 , pp, 303-317, London, and Churchill Livingstone.

13. Jindal UN, Dhall GI. Psychosexual Problems of infertile women in India. Int J Fertil.1996; 35:222-5.

14. Audu BM. Sexual dysfunction among infertile Nigerian women. J Obstet Gynaecol 2002;;22:655-7.

15. Jain K, Radhakrishnan G, Agrawal P. Infertility and psychosexual disorders: relationship in infertile couples. Indian J Med Sci.2000; 54:1-7.

16. Yassini SM. Incidence and prevalence of the sexual dysfunctions in fertile women, Thesis for medical doctor, Shahid Sadoughi University of Medical science, Yazd, Iran, 2003.

17. Ponholzer A, Roehlich M, Racz U, Temml C, Madersbacher S. Female Sexual dysfunction in a healthy Austrian cohort: prevalence and risk factors. J Urol .2005:174:364.

18. Ramezanzadeh F, Aghssa MM, Zayeri f. Alterations of sexual desire and satisfaction in male partners of infertile couples. Fertil Steril.2006; 85:139-43.

19. Ende J, Rockwell S, Glasgow M. The sexual history in general medical practice. Arch Intern Med 1984; 144:558561

Received on June 18, 2007; revised and accepted on July 3, 2007 